www.jmscr.igmpublication.org Impact Factor 5.244

Index Copernicus Value: 83.27 ISSN (e)-2347-176x ISSN (p) 2455-0450 crossref DOI:_https://dx.doi.org/10.18535/jmscr/v4i11.02

\title{
Pre-Hospital and in-ICU Mortality Predictors in Critically COPD Patients Admitted with Acute Respiratory Failure
}

\author{
Authors \\ Osama M Momtaz, MD; Ali O Abdelaziz, MD²; and Mohamed O Abdelaziz, $\mathbf{M D}^{3}$ \\ ${ }^{1}$ Critical Care Department, Faculty of Medicine, Fayoum University. ${ }^{2}$ Chest Department and ${ }^{3}$ Internal \\ Medicine Department, Faculty of Medicine, El-Minia University; Egypt
}

Corresponding Author

Osama M Momtaz, MD

Email: usamamomtaz@yahoo.com, Mobile +2/ 01224274142, +2/ 01155560083

\begin{abstract}
Background: Patients with COPD requiring admission to an intensive care unit (ICU) for acute respiratory failure $(R F)$ usually have a poor outcome especially when mechanical ventilation $(M V)$ is mandatory. Determining the factors predicting mortality is pivotal for tailoring monitoring, modifying therapy and more better management of modifiable risk factors after hospital discharge.

Objectives: To determine the pre-hospital and in-ICU predictors affecting mortality for critically COPD patients admitted with acute respiratory failure.

Methods: The study included 93 patients of COPD presented with acute respiratory failure admitted to the ICU. All patients were subjected to full medical history, general examination, pulmonary function tests, arterial blood gases analysis, laboratory investigations, chest imaging, echocardiography and assessment by Acute physiology and chronic health evaluation (APACHE II) scoring. Patients were followed up until ICU discharge or demise. Various pre-hospital and in-hospital comparative parameters studied in survivors and non-survivors of all included patients and in patients managed by $M V$ were analyzed and discussed.

Results: The overall mortality was $21.4 \%$. Sixty-two (66.7\%) of all studied patients were managed by invasive mechanical ventilation (IMV). The most frequently mortality predictors were requirement for $M V$, higher smoking index, higher body mass index, higher APACHE II scores, presence of corpulmolale, higher pulmonary artery pressure, lower systolic arterial blood pressure, associated or in-ICU developed cardiac arrhythmias, pre-hospital dependence on home oxygen, less frequent preadmission use of systemic corticosteroids, higher CRP, urea, creatinine and total leucocytic count, more prolonged ICU stay and development of complications due to mechanical ventilation. The most common cause of respiratory failure was acute COPD exacerbation which had a favorable ICU outcome, followed by pneumonia, sepsis and heart failure which were more predictive of mortality. Various comparative parameters were submitted and discussed.

Conclusion: We concluded that COPD patients admitted to ICU for acute RF are at substantial risk for hospital death. Important predictors related to hospital mortality should be thoroughly identified for proper modification and prophylaxis. Early identification of the high risk COPD patients is necessary for improving the ICU outcome by modifying management of the critically ill patients and may have the potential to decrease the rate of COPD decompensation after discharge by proper outpatient management.
\end{abstract}

Keywords: Severe COPD, ICU, mortality predictors, APACHE II score. 


\section{Introduction}

Chronic obstructive pulmonary disease (COPD) is a major cause of chronic morbidity and mortality throughout the world. Exacerbation of chronic obstructive pulmonary disease (COPD) is the fourth leading cause of death ${ }^{(1)}$ and expected to be ranked as the third one by $2020^{(2)}$. Patients with COPD requiring admission to an intensive care unit (ICU) for acute hypercapnic respiratory failure (RF) usually have a poor outcome in the case of a need for intubation, in particular. These patients have high mortality rates, with reported rates varying between $20 \%$ and $82 \%{ }^{(3,4)}$. These rates increase when ventilatory support becomes inevitable ${ }^{(5-9)}$.

Determining the factors predicting mortality is crucial because early identification of patients at high risk is essential for tailoring monitoring, modifying therapy and more better management of modifiable risk factors after hospital discharge. This study aimed to determine the pre-hospital and hospital predictors affecting mortality for critically COPD patients admitted to the ICU with acute respiratory failure.

\section{Patients and Methods}

The study included 93 patients of COPD presented with acute respiratory failure admitted in the general ICU of Fayoum University Hospital and the respiratory ICU of El-Minia University Hospital between October 2013 to October 2014. COPD was identified from the patient's history or the relatives with compatible physical examination and the patient's pulmonary function tests according to GOLD criteria (10) (post bronchodilator FEV1/FVC $<70 \%$ of predicted and reversibility of $<12 \%$ ). Acute respiratory failure was defined by sudden worsening of respiratory function with cyanosis, distress and signs of respiratory muscle exhaustion confirmed by blood gases $(\mathrm{PaO} 2<60 \mathrm{mmHg}$ with or without $\mathrm{PaCO} 2$ $>50 \mathrm{mmHg})^{(11)}$.

Exclusion criteria were one or more of the following: missing patient data, length of ICU stay of less than 24 hours, management by cardiopulmonary resuscitation on hospital admission, unestablished diagnosis of COPD including absence of previously documented PFTs or inability to perform during hospital stay.

All patients were examined within 24 hours of admission and subjected to the following:

(1) Full medical history as taken from all patients or their relatives with special emphasis to: age, sex, smoking status (non smoker, ex smoker or current smoker), smoking index (pack /year), history of previous hospital admission and or ICU admission, history of previous non invasive or invasive ventilator support, cardiopulmonary resuscitation before ICU admission, information about out-patient medical therapy as the use of bronchodilator, inhaled or long term oral steroid and home oxygen and other co-morbidities

(2) Clinical examination was performed to all patients including general examination with emphasis on signs of corpulmonale as well as local examination of the chest and heart. Body mass index (BMI) [Weight/(height $)^{2}$ in meters] was assessed in all patients.

(3) Pulmonary function tests (PFT) was assessed for all patients after stabilization of their clinical conditions. COPD patients had been classified according to the severity of COPD using the American Thoracic society (ATS) criteria (based on the percent predicted post-bronchodilator FEV1 when the FEV1/FVC is $<70 \%)^{(11)}$. Only stage IV patients were included.

(4) Arterial blood gases (ABG) analysis was done on admission and regularly as needed for patient diagnosis and follow up.

(5) Laboratory investigations including sputum examination and cultures, CBC (complete blood count), coagulation profile (PT, PC, INR and PTT), liver function tests [ALT (alanine aminotransferase), AST (aspartate aminotransferase), bilirubin and albumin], kidney function tests (urea, creatinine), blood sugar, serum electrolytes including $\mathrm{Na}, \mathrm{K}$ and calcium as well as other laboratory investigations according to the patient condition both on admission and then as needed. 
(6) Chest and cardiac imaging including plain $\mathrm{x}$ ray chest and echocardiography. CT chest was done for selected cases

(7) Acute physiology and chronic health evaluation (APACHE II).

All patients were evaluated according to the acute physiology and chronic health evaluation (APACHE II) scoring system at the time of admission ${ }^{(13)}$. The APACHE II score contains three components: age, acute physiologic score (APS), and chronic health. The total APACHE II score ranges from 0 to 71 . A higher score implies a less favorable prognosis. The APS includes physiologic variables and the Glasgow Coma Score (GCS). The 11 physiologic variables in the APS can contribute up to 4 points each. The patient's GCS can add a further 15 points. Immuno-compromised patients or those with severe organ system insufficiency receive 5 points for chronic health.

\section{Mechanical Ventilation}

We opted to manage the patients with invasive or non-invasive ventilation according to criteria for indications for intubation in acute $\mathrm{RF}^{(14)}$. These criteria were: (1) respiratory pauses or apnea with gasping for air or loss of consciousness or imminent respiratory arrest, (2) COPD acute exacerbation with hypercapnic RF, severe dyspnea or tachypnea plus at least one of the following (a) acute cardiovascular instability; (b) altered mental status of persistent uncooperativeness; (c) inability of lower airway protection or copious secretions; (d) inability to tolerate NIV or progressive respiratory acidosis despite intensive initial therapy. We began weaning from the MV as soon as the patient was capable of initiating a spontaneous breath and we started weaning by progressive reduction in pressure support ventilation as far as the patient could tolerate $^{(14)}$.

Patients were followed up until ICU discharge or demise. Various pre-hospital and in-hospital comparative parameters in survivors and non- survivors in all studied patients and in patients managed by MV were recorded.

Statistics: Descriptive statistics were computed for each of the variables analyzed. Results were presented as mean \pm SD. In order to compare the different groups; the dependent and independentsamples t-test for comparison between two groups and one way ANOVA with post hoc test for comparison between more than two groups were applied. Chi-squared test was used for comparison between categorical variables. All statistical analyses were performed using SPSS version 14.0 statistical software (SPSS Inc., Chicago, IL, USA). A probability value of $\mathrm{p}=0.05$ was used to determine statistical significance.

\section{Results}

This study included 93 COPD patients with acute exacerbations who were admitted in the ICU from October 2013 to October 2014. Four patients were excluded due to hospital discharge in less than 24 hours.

All studied patients were divided into 2 groups according to survival: group I (survivors) consisted of 74 patients (79.6\%) and group II (non-survivors) which included 19 patients (21.4\%). Sixty-two (66.7\%) of all studied patients were managed by invasive mechanical ventilation (IMV) : 46 of them (74.2\%) survived and 16 (25.8\%) were not survived contributing $84.2 \%$ of non-survivors for all studied patients ( $\mathrm{p}$ 0.001) whereas non-invasive ventilation (NIV) was sufficient in $31(33.3 \%)$ of all studied patients, 28 of them $(90.3 \%)$ survived and $3(9.7 \%)$ were not survived contributing $15.8 \%$ of non-survivors for all studied patients ( $\mathrm{p}$ 0.01) (table 1). 
Table (1): comparison of survivors and non-survivors and type of ventilation in the studied groups

\begin{tabular}{|l|c|c|c|}
\hline Parameter & $\begin{array}{c}\text { Group I(survivors) } \\
(\mathrm{n}=74)(79.6 \%)\end{array}$ & $\begin{array}{c}\text { Group II (non-survivors) } \\
(\mathrm{n}=19)(20.4 \%)\end{array}$ & P value \\
\hline IMV & $46(62.2 \%$ of survivors $)$ & $\begin{array}{c}16(84.2 \% \text { of non- } \\
\text { survivors })\end{array}$ & $0.001^{*}$ \\
\hline NIV & $28(37.8 .2 \%$ of survivors $)$ & $\begin{array}{c}3(15.8 \% \text { of non- } \\
\text { survivors })\end{array}$ & $0.01^{*}$ \\
\hline
\end{tabular}

IMV: invasive mechanical ventilation

NIV: non-invasive ventilation

* comparison between survivors and non-survivors

The demographic characteristics of the studied groups are illustrated in table (2). The mean age was $63.1 \pm 7.6$ years (range $44-76$ year), 72 of patients $(77.4 \%)$ were males, and 21 were females.

There was significantly higher smoking index in non-survivors in all patients and in non-survivors in invasively ventilated group. Current smoking was significantly higher in survivors compared to non-survivors in all patients but no significant difference was found between survivors and nonsurvivors in invasively ventilated (IV) patients. BMI was significantly higher in non-survivors both in all patients and in invasively ventilated group.

Table (2): the demographic characteristics of the studied groups

\begin{tabular}{|c|c|c|c|c|c|c|}
\hline $\begin{array}{l}\text { Demographic } \\
\text { characteristics }\end{array}$ & $\begin{array}{c}\text { Group I } \\
\text { (survivors) } \\
(\mathrm{n}=74)\end{array}$ & $\begin{array}{l}\text { Group II (non- } \\
\text { survivors) } \\
(\mathrm{n}=19)\end{array}$ & $\begin{array}{c}\mathrm{P} \\
\text { value }\end{array}$ & $\begin{array}{c}\text { Invasively ventilated } \\
\text { patients (survivors) } \\
(\mathrm{n}=46)\end{array}$ & $\begin{array}{c}\text { Invasively ventilated } \\
\text { patients (non- } \\
\text { survivors) }(\mathrm{n}=19)\end{array}$ & $\mathrm{P}$ value \\
\hline Age & $60 \pm 6.3$ & $63 \pm 4.2$ & 0.12 & $62 \pm 5.3$ & $64+7.2$ & 0.51 \\
\hline $\begin{array}{l}\text { Smoking history } \\
\text { index (pack/year) }\end{array}$ & $21 \pm 3.3$ & $27 \pm 5.4$ & 0.01 & $22 \pm 5.3$ & $26 \pm 5.2$ & 0.01 \\
\hline Smoker at admission & $52(70.3 \%)$ & $10(52.6 \%)$ & 0.01 & $23(50 \%)$ & $8(42 \%)$ & 0.32 \\
\hline
\end{tabular}

Differences of the baseline clinical and laboratory parameters on admission and during ICU stay as well as echocardiological parameter (pulmonary artery pressure) was assessed by univariate analysis for survivors versus non-survivors in all studied patients (n: 93) as well as for survivors versus non-survivors in patients received mechanical ventilation (n: 62) (table 3). It was found that 52 patients $(54.9 \%)$ had comorbidities which was significantly higher in non- survivors though no significant difference was found between survivors and non-survivors in IV patients. Right sided heart failure was associated in $35(37.7 \%)$ of all patients and was significantly higher is the non-survivor group and in the nonsurvivors of the IV subgroup. Hypertension was associated in 37 patients (39.8\% of all patients), diabetes mellitus in 28 patients $(30.1 \%)$ and chronic kidney disease in 6 patients $(6.5 \%)$ on admission and there was no significant statistical difference in these three comorbidities in group I and II as well as in survivors and non-survivors in IV patients. Cardiac arrhythmias were found in 15 patients $(16.1 \%)$ on admission and was significantly higher in group II and in nonsurvivors in IV patients.

Non-survivors had significantly higher APACHE II scores on admission than survivors both in all patients studied and in the IV patients. Receiving regular systemic steroid therapy on ICU admission was significantly higher in survivors than non-survivors and in survivors of IV patients whereas dependence on home oxygen therapy was significantly more in non-survivors. 
The most frequent cause of acute respiratory failure on admission was COPD exacerbation in $50.3 \%$ of the patients which was significantly higher in survivors $(55.4 \%)$ than non-survivors $(31.6 \%)$ even in survivors of IV patients. Pneumonia was the second cause and found in $19.3 \%$ of all patients and was significantly higher in non-survivors. Sepsis was the third cause and found in $15 \%$ with significantly more predilection in non-survivors. Heart failure was diagnosed as the cause of RF on admission in $10.7 \%$ of cases and was significantly more associated with nonsurvivors. Pulmonary embolism was diagnosed on admission in 2 cases $(2.1 \%)$, acute kidney injury in one case $(1.1 \%)$ and diabetic ketoacidosis in one case $(1.1 \%)$.

The length of ICU stay was significantly longer in non-survivors than in survivors including those managed by MV.

During the ICU stay, clinical and cardiologic parameters were obtained and analyzed including mean systolic blood pressure (SBP), mean pulmonary artery (PA) pressure and cardiac arrhythmias. It was found that PA pressure was significantly higher in non-survivors in all studied patients and in the subgroup of IV patients. SBP was also higher, though with lesser significance than PA pressure, in non-survivors. Cardiac arrhythmias developed during the ICU stay were significantly higher in non-survivors including those managed with MV.

The indications of intubation were respiratory pauses or apnea (35 patients; $56.5 \%$ ), respiratory failure with acute exacerbation of COPD associated with altered mental status with persistent unresponsiveness (14 patients; 22.6\%), intolerance to NIV with deteriorating respiratory acidosis (6 patients; 9.7\%), inability to clear secretions and urgent need to airway protection (4 patients; $6.5 \%$ ) and cardiovascular instability (3 patients; $4.8 \%$ )

Complications of MV occurred in 7 out of 62 of invasively ventilated patients $(11.3 \%)$ and were significantly more encountered in non-survivors. Complications included ventilator associated pneumonia in 5 cases, acute lung injury in one case and pneumothorax in one case.

Laboratory indices including $\mathrm{PaO}_{2}, \mathrm{PaCO}_{2}, \mathrm{PaO}_{2}$ $/ \mathrm{FiO}_{2}$ and $\mathrm{HCO}_{3}$, serum $\mathrm{Na}$, serum $\mathrm{K}$, as well as blood sugar were not significantly different between survivors and non-survivors as well as between invasively and non-invasively ventilated patients. CRP, WBCs as well as blood urea and serum creatinine were significantly higher in nonsurvivors compared to survivors and in invasively ventilated compared to non-invasively ventilated patients. 
Table (3): Differences assessed by univariate analysis in baseline clinical and laboratory data on admission and during ICU stay between survivors and non-survivors in all studied patients and in the mechanically ventilated group

\begin{tabular}{|c|c|c|c|c|c|c|}
\hline Parameters & $\begin{array}{l}\text { Group } \\
\text { I(survivors) } \\
(\mathrm{n}=74)\end{array}$ & $\begin{array}{l}\text { Group II } \\
\text { (non- } \\
\text { survivors) } \\
(\mathrm{n}=19)\end{array}$ & $\mathrm{P}$ value & $\begin{array}{l}\text { Invasively } \\
\text { ventilated } \\
\text { patients } \\
\text { (survivors) } \\
(\mathrm{n}=46) \\
\end{array}$ & $\begin{array}{l}\text { Invasively } \\
\text { ventilated } \\
\text { patients (non- } \\
\text { survivors) }(\mathrm{n}=16)\end{array}$ & $\mathrm{P}$ value \\
\hline $\begin{array}{l}\begin{array}{l}\text { Number of previous } \\
(\text { mean }+\mathrm{SD})\end{array} \\
\end{array}$ & $2.3 \pm 1.2$ & $1.6 \pm 0.8$ & 0.03 & $2.45 \pm 1.3$ & $2.23 \pm 1.32$ & NS \\
\hline $\begin{array}{l}\text { Type of comorbidities } \\
\text { right sided heart failure,no (\%)\#* } \\
\text { hypertension ,no (\%)\#* } \\
\text { diabetes mellitus ,no }(\%) \# * \\
\text { chronic kidney disease ,no }(\%) \# * \\
\text { Cardiac arrhythmias,no }(\%)^{* \#} \\
\text { Others ,no }(\%) \#^{*}\end{array}$ & $\begin{array}{l}21(28.4 \%) \\
30(40.5 \%) \\
22(29.7 \%) \\
4(5.4 \%) \\
8(10.8 \%) \\
7(9.5 \%)\end{array}$ & $\begin{array}{l}14(73.6 \%) \\
7(36.8 \%) \\
6(31.6 \%) \\
2(10.5 \%) \\
7(36.8 \%) \\
4(21.1 \%)\end{array}$ & $\begin{array}{l}<0.001 \\
\text { NS } \\
\text { NS } \\
\text { NS } \\
0.01 \\
0.01\end{array}$ & $\begin{array}{l}15(32.6 \%) \\
16(34.7 \%) \\
15(32.6 \%) \\
3(6.5 \%) \\
6(13 \%) \\
5(10.6 \%)\end{array}$ & $\begin{array}{l}12(75 \%) \\
5(31.2 \%) \\
6(37.5 \%) \\
2(12.5 \%) \\
6(37.5 \%) \\
3(18.7 \%)\end{array}$ & $\begin{array}{l}<0.001 \\
\text { NS } \\
\text { NS } \\
\text { NS } \\
0.01\end{array}$ \\
\hline APACHE II score $($ mean \pm SD) \# & $23.3 \pm 5.3$ & $28.2 \pm 4.9$ & $<0.001$ & $24.1 \pm 4.9$ & $28.2 \pm 5.1$ & $<0.001$ \\
\hline $\begin{array}{l}\text { Systemic corticosteroid use on admission, no } \\
(\%) \#\end{array}$ & $35(47.3 \%)$ & $7(36.8 \%)$ & 0.01 & $25(54.3 \%)$ & $5(31.2 \%)$ & $<0.001$ \\
\hline $\begin{array}{l}\text { Dependence on home oxygen before } \\
\text { admission, no }(\%) \#\end{array}$ & $21(28.4 \%)$ & $10(52.6 \%)$ & $<0.001$ & $12(26.0 \%)$ & $7(43.7 \%)$ & 0.01 \\
\hline $\begin{array}{l}\text { Cause of acute RF: } \\
\text {-COPD exacerbation, no }(\%) \\
\text {-pneumonia, no }(\%) \\
\text {-sepsis, no }(\%) \\
\text {-cardiac failure, no }(\%) \\
\text {-others ,no }(\%)\end{array}$ & $\begin{array}{l}41(55.4 \%) \\
13(17.6 \%) \\
10(13.5 \%) \\
6(8.1 \%) \\
4(5.4 \%)\end{array}$ & $\begin{array}{l}6(31.6 \%) \\
5(26.3 \%) \\
4(21 \%) \\
4(21 \%) \\
0(0 \%)\end{array}$ & $\begin{array}{l}<0.001 \\
0.01 \\
0.01 \\
0.01 \\
<0.001\end{array}$ & $\begin{array}{l}28(54.3 \%) \\
10(21.7 \%) \\
4(8.7 \%) \\
2(4.3 \%) \\
2(4.3 \%)\end{array}$ & $\begin{array}{l}5(31.2 \%) \\
4(25 \%) \\
4(25 \%) \\
3(18.8 \%) \\
0(0 \%)\end{array}$ & $\begin{array}{l}<0.001 \\
\text { NS } \\
0.001 \\
0.01 \\
0.001\end{array}$ \\
\hline Length of ICU stay (days) (mean \pm SD) & $8.3 \pm 3.1$ & $12.5 \pm 2.3$ & $<0.001$ & $7.9 \pm 3.2$ & $12.3 \pm 5.3$ & $<0.001$ \\
\hline $\begin{array}{l}\text { Clinical and cardiac parameters: } \\
\text { PA pressure (mmHg) (mean } \pm \text { SD) } \\
\text { SBP (mean } \pm \text { SD) } \\
\text { cardiac arrhythmias,no }(\%)^{* *} \\
\text { complications of MV, no }(\%)\end{array}$ & $\begin{array}{l}47 \pm 6.3 \\
132 \pm 26 \\
13(17.6 \%) \\
3(4.0 \%)\end{array}$ & $\begin{array}{l}56 \pm 7.4 \\
121 \pm 22 \\
12(63.2 \%) \\
4(21 \%) \\
\end{array}$ & $\begin{array}{l}<0.001 \\
0.04 \\
<0.001 \\
<0.001 \\
\end{array}$ & $\begin{array}{l}48 \pm 5.23 \\
129 \pm 24 \\
9(19.6 \%) \\
3(6.5 \%) \\
\end{array}$ & $\begin{array}{l}58 \pm 6.21 \\
119 \pm 28 \\
10(62 \%) \\
4(25 \%) \\
\end{array}$ & $\begin{array}{l}<0.001 \\
0.03 \\
<0.001 \\
<0.001 \\
\end{array}$ \\
\hline 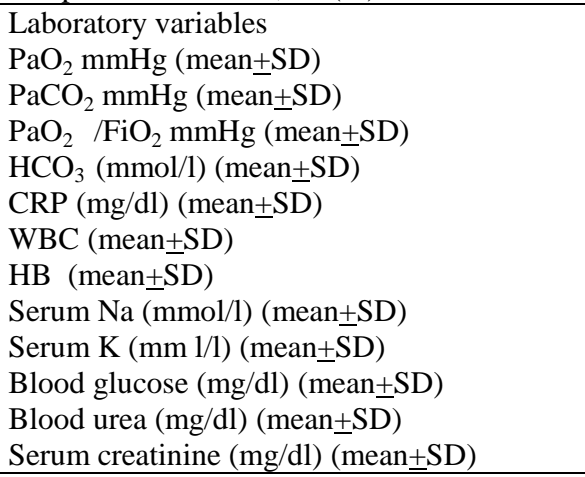 & $\begin{array}{c}55.5 \pm 7.1 \\
69.5 \pm 8.1 \\
175.5 \pm 9.1 \\
7.25 \pm 0.10 \\
17.9 \pm 6.3 \\
14.9 \pm 5.7 \\
13.9 \pm 2.1 \\
139 \pm 3.2 \\
4.9 \pm 0.2 \\
185 \pm 29 \\
45 \pm 13 \\
1.4 \pm 0.5\end{array}$ & $\begin{array}{l}57.5 \pm 6.9 \\
67.5 \pm 7.5 \\
187.5 \pm 7.9 \\
7.20 \pm 0.13 \\
20.5 \pm 5.6 \\
17.3 \pm 5.4 \\
12.8 \pm 2.4 \\
141 \pm 2.2 \\
4.8 \pm 0.3 \\
175 \pm 21 \\
58 \pm 16 \\
1.9 \pm 0.6 \\
\end{array}$ & $\begin{array}{l}\text { NS } \\
\text { NS } \\
\text { NS } \\
\text { NS } \\
0.01 \\
0.01 \\
\text { NS } \\
\text { NS } \\
\text { NS } \\
\text { NS } \\
0.01 \\
0.02 \\
\end{array}$ & $\begin{array}{l}56.6 \pm 26.5 \\
65.5 \pm 7.1 \\
182.5 \pm 6.7 \\
7.24 \pm 0.12 \\
16.8 \pm 7.1 \\
15.7 \pm 4.7 \\
13.5 \pm 2.6 \\
140 \pm 2.9 \\
5.0 \pm 0.2 \\
175 \pm 32 \\
39 \pm 17 \\
1.5 \pm 0.4 \\
\end{array}$ & $\begin{array}{l}55.5 \pm 7.2 \\
70.5 \pm 7.5 \\
190.5 \pm 8.7 \\
7.23 \pm 0.14 \\
21.9 \pm 6.2 \\
18.9 \pm 4.6 \\
12.9 \pm 2.2 \\
142 \pm 3.1 \\
4.9 \pm 0.2 \\
182 \pm 30 \\
73 \pm 21 \\
2.1 \pm 0.5 \\
\end{array}$ & $\begin{array}{l}\text { NS } \\
\text { NS } \\
\text { NS } \\
\text { NS } \\
0.01 \\
0.01 \\
\text { NS } \\
\text { NS } \\
\text { NS } \\
\text { NS } \\
0.01 \\
0.01 \\
\end{array}$ \\
\hline
\end{tabular}

$*$ number and percentage of comorbidities in relation to the number affected in survivors compared to non-survivors in all studied patients and the number affected in survivors compared to non-survivors in invasively ventilated patients. More than one comorbidiy in the same patient were sometimes present.

\# parameters assessed before or on admission. Unmarked parameters were assessed during the ICU stay

** all cardiac arrhythmias both diagnosed on admission and developed during ICU stay

RF : respiratory failure, PA: pulmonary artery, SBP: systolic blood pressure, CRP: C reactive protein , WBC: white blood cells, HB: hemoglobin

\section{Discussion}

This study included 93 patients of COPD presented with acute respiratory failure admitted in the general ICU of Fayoum University Hospital and the respiratory ICU of El-Minia University Hospital. The ICU mortality of COPD patients with respiratory failure in this study was $20.4 \%$. This rate was $9.7 \%$ in patients only and sufficiently managed by NIV whereas it was $25.8 \%$ in patients needed IMV. This reflects the need of most of the severely critically-ill patients for IMV and the proper response of less critically- 
ill patients for NIV. The mortality rate of patients with COPD and acute RF reported by different studies ranged between $6 \%$ and $24 \%$ for those requiring ICU,2-14 and it was $14-57 \%$ in patients requiring $\mathrm{MV}{ }^{(5-9)}$.

The significantly higher smoking index in nonsurvivors in all patients and in non-survivors in invasively ventilated group emphasizes the wellknown deleterious effect of smoking on COPD severity. It should be noted that current smoking was significantly higher in survivors compared to non-survivors. This may be explained by the less critical state of the survivors that allowed them to be still tolerable to smoking compared to the severely ill patients who were mostly nontolerable to smoking and this highlights the difficulties facing the Egyptian physicians, media and health authorities in inducing COPD patients, including even patients with RF, to stop smoking. Mortality was found to be significantly higher both in all patients and in invasively ventilated group with higher BMI. This supports the growing evidence of the link between morbid obesity COPD severity ${ }^{(15)}$ and poor response to therapy and the role of weight reduction in improving outcome of COPD ${ }^{(16)}$.

Our study identified several independent risk factors increasing ICU mortality using information obtainable from the univariate analysis. Presence of associated co-morbidities detected on ICU admission was associated with increased hospital mortality including right sided heart failure and cardiac arrhythmias, both conditions are assumed to be related to disease severity coming in accordance with other studies $(8,11,18)$. Hypertension, diabetes mellitus and chronic kidney disease diagnosed on admission did not carry more significant risk of ICU mortality. However, the mean serum urea and creatinine measured during ICU stay, reflecting recent kidney injury, was significantly higher in non-survivors and hence carrying more worse outcome. The same was also found by the decreased mean systolic blood pressure as well as the occurrence of recently developed cardiac arrhythmias, both were predictive of increased ICU mortality. The mean pulmonary artery pressured measured during ICU stay as well as developed complications of mechanical ventilation were also associated with increased mortality. Our study found that high APACHE II score had carried more mortality risk in all studied patients as well as in IV patients coming in accordance with many other studies ${ }^{(17-19)}$. Patients who had been on regular intake of systemic corticosteroids therapy on the ICU admission had more favorable outcome. This comes in accordance with recent evidence of the beneficial effect of systemic corticosteroids on outcome of COPD patients admitted to the ICU ${ }^{(20)}$.

We found that dependence on home oxygen had carried more mortality risk in all studied patients as well as in MV patients. This may reflect the disease severity in one aspect and the deleterious effect of inappropriate oxygen therapy on disease progression $^{(21)}$ in the other aspect.

Analysis of the relation of cause of acute respiratory failure and mortality showed that patients presented with pneumonia, sepsis or cardiac failure had more worse outcome compared to those presented with COPD exacerbation who had more favorable outcome.

The length of ICU stay was significantly longer in non-survivors than in survivors including those managed by MV. This had been previously reported by different studies as a significant predictor of in-hospital mortality $(11,18,19,22,23)$.

Laboratory indices including mean of $\mathrm{PaO}_{2}$, $\mathrm{PaCO}_{2}, \mathrm{PaO}_{2} / \mathrm{FiO}_{2}$ and $\mathrm{HCO}_{3}$, serum $\mathrm{Na}$, serum $\mathrm{K}$, as well as blood sugar were not significant predictors of mortality whereas high CRP and WBCs were found as significant predictors of ICU mortality. This correlates with some other studies $(11,18,19,22)$ whereas it shows differences with other ones ${ }^{(11,24,25)}$.

$\mathrm{MV}$ is a lifesaving procedure in patients with acute RF. It was undergone in $66.7 \%$ of our patients. Complications of MV was encountered in $11.3 \%$ of $\mathrm{MV}$ patients carrying a significant predictor of ICU mortality with a significantly 
higher rate in non-survivors $(25 \%)$ compared to survivors $(6.5 \%)$. In other studies, 22-85\% patients with acute exacerbation of COPD needed invasive MV and patients managed by MV had a mortality rate varying between $20-82 \%{ }^{(22-25)}$.

We concluded that COPD patients admitted to ICU for acute RF are at substantial risk for hospital death. Important predictors related to hospital mortality are the need for invasive ventilation and complications to MV. Presence of comorbidities, mainly right sided heart failure and cardiac arrhythmias on admission or occurrence of cardiac arrhythmias, heart failure, deterioration of kidney function are also predictive of mortality. High APACHE II score, high BMI, history of high smoking index , ICU presentation with certain causes of RF mainly pneumonia and sepsis as well as high CRP and WBC count carry more worse outcome. We recommend that these factors should be thoroughly identified for proper modification and prophylaxis. Early identification of the high risk COPD patients is necessary for improving the ICU outcome by modifying management of the critically ill patients and also has the potential to decrease the rate of COPD decompensation after discharge by proper outpatient management.

\section{References}

1. Patil SP, Krishnan JA, Lechtzin N, Diette GB. In hospital mortality following acute exacerbations of chronic obstructive pulmonary disease. Arch Intern Med 2003;163:1180-6.

2. Global Initiative for Chronic Obstructive Lung Disease [homepage on the Internet]. Bethesda: Global Initiative for Chronic Obstructive Lung Disease. [cited 2010 Feb 03]. Global Strategy for Diagnosis, Management and Prevention of COPD. Updated 2008.

3. Steer J, Gibson GJ, Bourke SC. Predicting outcomes following hospitalization for acute exacerbations of COPD. QJM. 2010;103(11):817-29.
4. Jezler S, Holanda MA, José A, Franca S. Mechanical ventilation in decompensated chronic obstructive pulmonary disease (COPD) [Article in Portuguese]. J Bras Pneumol. 2007;33 Suppl 2S:S111-8.

5. Fuso L, Incalzi RA, et al. Predicting mortality of patients hospitalized for acutely exacerbated chronic obstructive pulmonary disease. Am J Med 1995;98:272-7.

6. Afessa B, Morales IJ, Scanlon PD, Peters SG. Prognostic factors, clinical course, and hospital outcome of patients with chronic obstructive pulmonary disease admitted to an intensive care unit for acute respiratory failure. Crit Care Med 2002;30:1610-5.

7. Seneff MG, Wagner DP, Wagner RP, Zimmerman RP, Zimmerman JE, Knaus WA. Hospital and 1-year survival of patients admitted to intensive care units with acute exacerbation of chronic obstructive pulmonary disease. J Am Med Assoc 1995;274:1852-7.

8. Esteban A, Anzueto A, Frutos F, et al. Mechanical Ventilation International Study Group. Characteristics and outcomes in adult patients receiving mechanical ventilation: a 28-day international study. J Am Med Assoc 2002;287:345-55.

9. Nevins ML, Epstein SK. Predictors of outcome for patients with COPD requiring invasive mechanical ventilation. Chest 2001;119:1840-9.

10. (NHLBI/WHO. Global Initiative for Chronic Obstructive Lung Disease (GOLD) Workshop,2009: Global strategy for the diagnosis management, and prevention of Chronic Obstructive Pulmonary Disease. 2009 update. Available from: http://www.goldcopd.com.

11. Ucgun I_, Metintas M, Moral H, Alatas F, Yildirim $\mathrm{H}$, Erginel $\mathrm{S}$. Predictors of hospital outcome and intubation in COPD patients admitted to the respiratory ICU 
for acute hypercapnic respiratory failure. Respiratory Medicine (2006) 100, 66-74.

12. Qaseem A, Wilt TJ, Weinberger SE, Hanania NA, Criner G, van der Molen T, Marciniuk DD, et al. Diagnosis and Management of Stable Chronic Obstructive Pulmonary Disease: A Clinical Practice Guideline Update from the American College of Physicians, American College of Chest Physicians, American Thoracic Society, and European Respiratory Society. Ann Intern Med. 2011;155:179-191.

13. Zimmerman J, Kramer A, McNair A et al. Acute Physiology and Chronic Health Evaluation (APACHE). : ICU length of stay benchmarks for today's critically ill patients. Critical Care Med. 2006; 34:2517-2529.

14. Pierson DJ. Invasive mechanical ventilation. In: Albert RK, Spiro SG, Jett JR, editors. Clinical respiratory medicine. Philadelphia, PA: Mosby Publishers; 2004. p. 189-209.

15. Denis E. O'Donnell, Casey E. Ciavaglia, and J. Alberto Neder "When Obesity and Chronic Obstructive Pulmonary Disease Collide. Physiological and Clinical Consequences", Annals of the American Thoracic Society, Vol. 11, No. 4 (2014), pp. 635-644. doi: 10.1513/AnnalsATS.201312-438FR

16. Basem I. El-Shafey B and El-Deib A. Effect of weight reduction on obese patients with COPD and bronchial asthma. Open Access funded by The Egyptian Society of Chest Diseases and Tuberculosis doi:10.1016/j.ejcdt.2015.06.007

17. Groenewegen KH, Schols AM, Wouters EF. Mortality and mortality-related factors after hospitalization for acute exacerbation of COPD. Chest. 2003;124(2):459-67.

18. Raurich JM, Pérez J, Ibáñez J, Roig S, Batle S. In-hospital and 2-year survival of patients treated with mechanical ventilation for acute exacerbation of COPD. Arch Bronconeumol. 2004;40 (7): 295-300.

19. Teixeira C, Cabral CdR, Hass JS, Pinheiro de Oliveira R, Vargas MA et al. Patients admitted to the ICU for acute exacerbation of COPD: two-year mortality and functional status. J Bras Pneumol. 2011;37 (3):334-340

20. Abroug F, Ouanes I, Abroug S, Dachraoui F, Abdallah SB, Hammouda $Z$ and Ouanes-Besbes L. Systemic corticosteroids in acute exacerbation of COPD: a meta-analysis of controlled studies with emphasis on ICU patients. Annals of Intensive Care2014;4:32

21. Ringbaek TJ, Terkelsen J and Peter Lange $P$. Outcomes of acute exacerbations in COPD in relation to pre-hospital oxygen therapy. European Clinical Respiratory Journal 2015, 2: 27283 http://dx.doi.org/10.3402/ecrj.v2.27283

22. Conlon N, O'Brien B, Herbison GP, Marsh B. Long-term functional outcome and performance status after intensive care unit re-admission: a prospective survey. $\mathrm{Br}$ J Anaesth. 2008;100(2):219-23.

23. Hilbert G, Gruson D, Vargas F, et al. Noninvasive ventilation in immunosuppressed patients with pulmonary infiltrates, fever and acute respiratory failure. N Engl J Med 2001;344:481-487.

24. Euteneuer S, Windisch W, Suchi S, Köhler D, Jones PW, Schönhofer B. Healthrelated quality of life in patients with chronic respiratory failure after long-term mechanical ventilation. Respir Med. 2006;100(3):477-86.

25. Hough CL, Curtis JR. Long-term sequelae of critical illness: memories and healthrelated quality of life. Crit Care. 2005;9(2):145-6 